\title{
Multiple Home-to-Home Energy Transactions for Peak Load Shaving
}

\author{
Khizir Mahmud, M. S. H. Nizami, Student Member, IEEE, Jayashri Ravishankar, MJ Hossain and \\ Pierluigi Siano, Senior Member, IEEE
}

\begin{abstract}
This paper proposes a new technique to manage the domestic peak load demand through peer-to-peer (P-P) energy transaction among multiple homes. In this process, the houses willing to sell energy are identified as the Parent, and the houses that require energy are identified as a Child. The parents having energy resources such as photovoltaics $(\mathrm{PV})$, battery storage and electric vehicles (EVs) will utilize their resources to meet their peak power demand and sell the extra energy to a child. A mixed integer linear programming optimization is used to find the parent-child matching based on their energy availability, power demand and distances. After selecting the parent-child match, the power demand of a child is forecasted using two different techniques, i.e. autoregressive moving average and artificial neural networks, to identify to child's need in a day ahead of the actual operation. The proposed algorithm calculates the available energy of a parent to sell in real-time and the required energy of a child in a day-ahead, while ensuring to minimize the peak load demand. The proposed method, as confirmed by the presented analysis using data of a real Australian power distribution network, is able to significantly minimize the peak load demand, which in-turn is expected to minimize the electricity costs. The method also facilitates two agreed prosumers to transact energy between themselves without the involvement of a third party.
\end{abstract}

Index Terms--Demand management, peak load management, peak shaving, peer-to-peer energy transactions, prosumers.

\section{NOMENCLATURE}

Indices and Sets

$\begin{array}{ll}p, c \in M & \text { Participating consumers } \\ \mathrm{t} & \text { Time periods }\end{array}$

\section{Parameters}

$D_{p, c}^{m} \quad$ Distance between parent, $p$ and child, $c$ in km

$R_{p, c}^{m} \quad$ Line resistance between parent, $p$ and child, $c$

$\hbar_{p}^{t} \quad$ Set-point value to define peak and off-peak demand of a parent

$\Gamma_{p, b}^{c}, \Gamma_{p, e v}^{c}$, The capacity of battery storage, electric vehicle and $\wp_{p v, p}^{t} \quad$ photovoltaics, respectively that belongs to a parent.

$\alpha_{p, b}^{\max }, \alpha_{p, e v}^{\max } \quad$ Upper charging boundary of battery storage and electric vehicle of a parent, respectively

$\alpha_{p, b}^{\min }, \alpha_{p, e v}^{\min } \quad$ Lower discharging boundary of the battery and EV, respectively.

Khizir Mahmud and Jayashri Ravishankar are with the School of Electrical Engineering and Telecommunications, University of New South Wales, NSW 2052, Australia, email: khizir.mahmud@unsw.edu.au, jayashri.ravishankar@unsw.edu.au.

MSH Nizami is with the School of Engineering, Macquarie University, NSW 2109, Australia, email: sohrab.nizami@hdr.mq.edu.au.

Professor Pierluigi Siano is with the Department of Management \& Innovation Systems, University of Salerno, Italy, email: psiano@unisa.it. $\hbar_{c}^{t}$

Set-point of a child to identify its power purchase requirement

Variables

$F_{p, c}^{1} \quad$ Energy transfer losses from parents to children

$F_{p, c}^{2} \quad$ Differences between a parent's energy generation capability and the demand of a child

$\mathcal{L}_{p}^{t} \quad$ Power demand of a parent

$\chi_{p=1,2, \ldots, m}^{a v} \quad$ Power available from parents

$\chi_{c=1,2, \ldots . . m}^{r e q} \quad$ Requested power from children

$\chi_{p=1,2, \ldots, m}^{\text {capacity }}$

$\aleph_{p}^{a v} \quad$ Available power (during off-peak hours) for a parent to charge battery storage and electric vehicle

$\alpha_{p, b}^{i}, \alpha_{p, e v}^{i} \quad$ Current state-of-charge of battery storage and electric vehicle respectively

$\aleph_{p}^{r e q} \quad$ Required power (during peak hours) by a parent to shave peak, which is met by the battery storage, electric vehicle and PV

$\mathcal{E}_{p-c}^{p} \quad$ The maximum amount of power a parent can share with its child

$u, v \quad$ Order of the ARMA model

$x_{p, c} \quad$ Optimal parent-child combination for minimum power transfer loss during the p-p energy trading

$\mathbb{Z}_{t} \quad$ Forecasting output from ARMA and ANN

$\mathcal{L}_{c}^{t} \quad$ Forecasted power demand of a child

$\mathcal{E}_{c-p}^{c} \quad$ Requested amount of power by a child to purchase

\section{INTRODUCTION}

$\mathrm{T}$ HE electrical power system is going through a dramatic transformation predominantly due to the rapid proliferation of renewable energy resources (RES) [1]. A significant portion of RESs are small-scale distributed generators (DG) being installed close to the consumers. Despite substantial contributions towards greenhouse gas reductions, RESs raise reliability concerns for the utilities due to their intermittency and volatile nature [2]. Consequently, the utilities can reduce the dependency on the expensive peaking power plants, also contributing to reduce the electricity costs [3].

However, most small-scale electrical battery storage systems are connected behind the energy meter of the consumers. Various energy management systems (EMS) manage these battery storages along with on-site DG (e.g. rooftop solar photovoltaics units) based on time-varying tariffs to reduce the consumers' electricity costs [4], [5]. Moreover, the integration of electric vehicles (EVs) and their bidirectional energy transactions using vehicle-to-grid (V2G) technology can also support the domestic EMS to further reduce the electricity costs [4]. 
In an evolving market structure, some advanced features of EMS also provides provision for selling back extra energy to the grid thereby transforming customers to prosumers. With the introduction of local electricity markets, the prosumers can also participate in local energy transactions, especially neighbourhood energy transactions using peer-to-peer (P-P) processes [6]. Smart, intelligent and regulated P-P systems can provide the full benefit of the local energy trading to both consumers and utilities. In this P-P process, prosumers can eliminate the utilities or any middle entity, and carry out the energy transaction process between two parties. In a largescale, virtual power plants (VPPs) aggregate the small-scale prosumers and sell back their extra energy to the grid during peak load hours [7]. Thus, the utilities can leverage on prosumers' energy supply flexibility to shave the peak demand and potentially minimize the risk of the distribution transformer oversaturation [6], [8]. It is expected that the future smart grid and smart city, and the internet-of-energy (IoE) will facilitate more P-P energy transaction systems through VPPs and by empowering consumers to participate in local energy markets. However, the unregulated energy transaction process and the use of various intermittent renewables will challenge VPPs to provide reliable electricity. Moreover, the use of various EMSs and P-P systems will make the power flow more complex and unpredictable [6].

\section{A. Literature}

In recent years, there has been an increasing amount of published studies on the peer-to-peer energy transactions [9][12], where an energy sharing model neglecting the intermediate layers is proposed. Most of these models cover three main areas, multi-agent-based modeling [10], analytical modeling [11], [12], and auction modeling [9]. The multiagent-based approach was used to monitor and control the distributed energy resources (DERs), their reverse auction process, and schedule the DER unit commitment within an hour-ahead market environment. Analytical models of local market electricity prices considering DERs and specific rules include intensive methods, shared energy calculation processes, and power-sharing negotiation process using game theory [13]. The auction modeling process considered the internal pricing mechanism, supply demand ratio (SDM), and the role of the local market operator that collects the bidding information and provides the pricing signals to the individual customers. The game theoretic approach [14] is widely used when discussing the control and optimization process of P-P energy sharing considering various players and market mechanisms including DERs and prosumers [15].

The performance tests of research activities considered different types and scales of the grid, for example, community microgrids, stand-alone microgrids, and grid-connected microgrids. Some researchers focused on P-P energy trading within a community-based microgrid [6], [16]. For a community microgrid shared by a few numbers of customers located in close vicinity, authors described a suitable P-P model, considering customers demand and the generation capability of distributed energy resources (DERs), that can bring benefits to all the parties. Authors in [17], tested the P-P energy trading approach for a grid-connected microgrid for balancing the energy generation and consumers' demand [18]. A study in [19], presented a neighborhood energy transaction process with two homes. However, the performance of the proposed system under multiple customers and their optimal energy transaction process using optimization techniques were not considered. In [12], a price-based demand response model implementing the P-P energy sharing in microgrids is proposed. An important step for the internal demand management of prosumers is the evaluation of the excess energy of a prosumer to trade. Demand management mainly focuses on either shifting controllable loads [20] or managing local energy resources [21] such as photovoltaics (PV) [22], battery storage and electric vehicles (EV). A study in [23], presented an approach to minimize the peak load using a controlled charging-discharging of EV and battery storage. However, this research was limited to a single home peak load reduction, therefore, the extra energy after meeting own demand was not utilized in the neighborhood energy transaction processes.

Studies have focused on developing distributed architecture for enabling p-p trading. For example, Blockchain-based local trading model is presented in [24] to provide ancillary service in terms of voltage regulation. A bilateral contract-based $p-p$ energy trading model is presented in [25] using a multi-agent system that optimizes prosumers' trading bids to maximize their profits. A consensus-based methodology is presented in [26] for p-p local markets. Multi-agent-based methodologies for local energy trading or sharing are also adopted in [27] and [28]. Many researchers concentrated on the P-P energy transactions pricing mechanism [29] such as social-welfarebased optimization approach [30], mid-market rate (MMR) method [17], and SDR approach [12]. Other researches focused on the market mechanism of P-P energy trading, such as bilateral contract networks for P-P energy trading [25]. In such a study, a real-time forward market is introduced considering the energy contracts between consumers (having flexible and non-flexible loads and renewables), suppliers and generators.

Although, game theoretic and blockchain-based approaches are widely used, they require complex and frequent communication. There are P-P based studies proposing bidding mechanisms and pricing models for local trading or sharing, which requires complex computation thereby making them infeasible for real-world application with marketavailable embedded devices. Most studies focused on the cost minimization for the consumers, which can introduce rebound peaks. Coordinated methods or active transactive trading can solve this issue [18], [27], however, such methods require a coordinating entity to oversee the transaction mechanisms.

To overcome the above issues, this paper introduces a local $\mathrm{p}-\mathrm{p}$ trading mechanism to address peak demand without the need for such coordinating entity. The method used is simple and requires minimum communication. The computations are simple, making it feasible for real-world applications with market-available embedded devices. 


\section{B. Novelty and contributions}

In contrast to previous researches, this study focuses on the P-P energy transactions process for peak load management. The novel contributions of the proposed method are as follows:

- A p-p energy transaction framework is designed where customers willing to sell energy and consumers interested to buy energy can identify their pairing considering minimum distance and minimum demandgeneration differences.

- $\quad$ A method for peak load shaving through P-P energy sharing process is proposed.

- A day-ahead power demand system for the customers interested to buy energy and the real-time peak power demand management systems for the customers willing to sell energy are proposed.

The proposed model identifies the potential energy sellers and buyers and facilitates their matching process. After selecting the potential prosumers, the power demand of a buyer is forecasted using two different techniques, i.e. autoregressive moving average and artificial neural networks. These forecasting processes help sellers to easily calculate the energy requirements of its buyers without having a real-time communication arrangement. The proposed method is analyzed using data of a real Australian power distribution network and the results demonstrated that it can significantly minimize the peak load demand.

\section{Organization of the Paper}

The remaining parts of the paper are organized as below. Section II gives an overview of the proposed P-P energy transactions process, Section III discusses the management algorithm, and Section IV presents various case studies followed by conclusions in Section V.

\section{P-P ENERGy TRANSACTIONS OVERVIEW}

\section{A. Characteristics of Prosumers}

Based on the energy requirements and energy generation capability, prosumers are categorized into three, energy buying, standalone and energy selling prosumers, as shown in Figure 1.

- Energy Buying Prosumers: These types of prosumers do not have or have minimal energy resources, and they are willing to buy energy from other prosumers. They tend to depend on the grid during off-peak hours and buy energy from other prosumers during peak load hours to reduce their electricity costs. They usually send requests to potential neighbouring prosumers who meet the requirements and are willing to sell extra energy [31].

- Standalone Prosumers: These types of prosumers may have a limited energy generation capability; however, they do not have surplus energy to trade. So, they do not participate in the prosumers' energy buying and selling process [31].
- Energy Selling Prosumers: These type of prosumers have several energy resources such as roof-top PVs, battery storage and EVs. They have a surplus of energy from these resources and fulfil requirements to sell energy to their neighbours. In typical cases, these type of prosumers do not buy energy from other prosumers; however, occasionally, they may buy energy from other energy selling prosumers having higher energy generation capability [31].

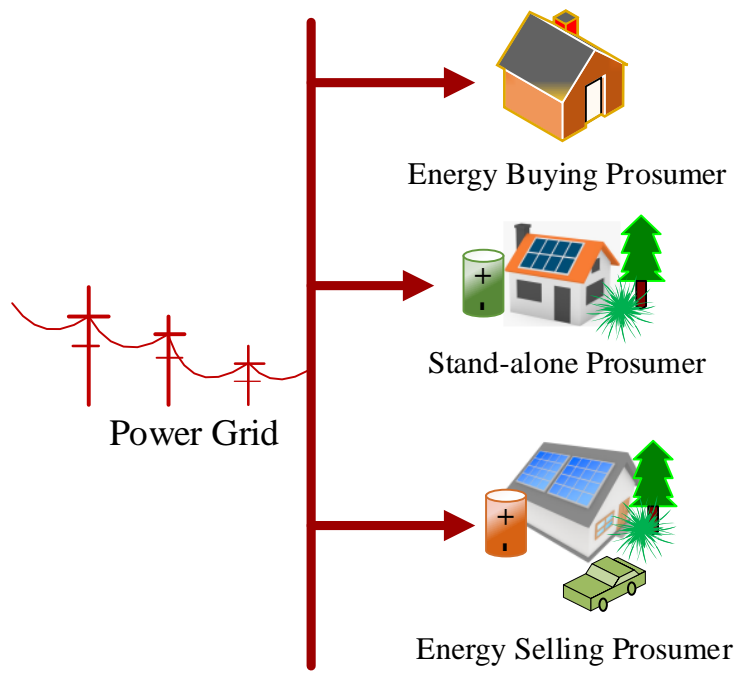

Fig. 1. Categories of prosumers.

\section{B. P-P Energy Transactions Among Prosumers}

In the P-P energy transaction process, the energy selling prosumers are identified as 'parent', and the energy buying prosumers are identified as 'child', as shown in Figure 2. The parents (having energy resources) utilize their resources (PV, $\mathrm{EV}$, battery storage) to meet their peak power demand. A parent, after meeting its demand, can share the excess energy with a child. The knowledge of the energy requirements of a child is therefore important. Based on the available energy of parents and the energy required by the children, the proposed method searches the best parent-child matches. Figure 3 shows the parent-child searching process.

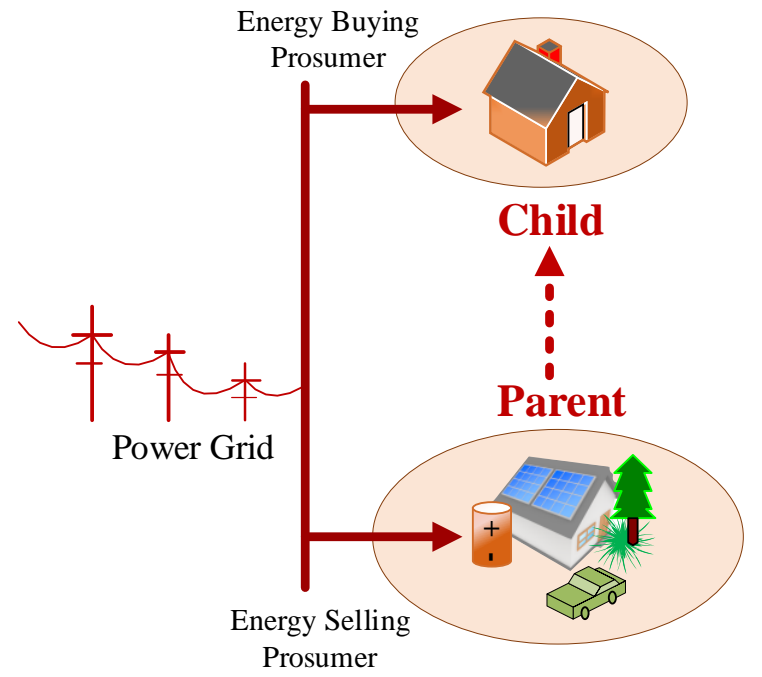

Fig. 2. The parent-child relationship between energy buying and energy selling prosumers. 


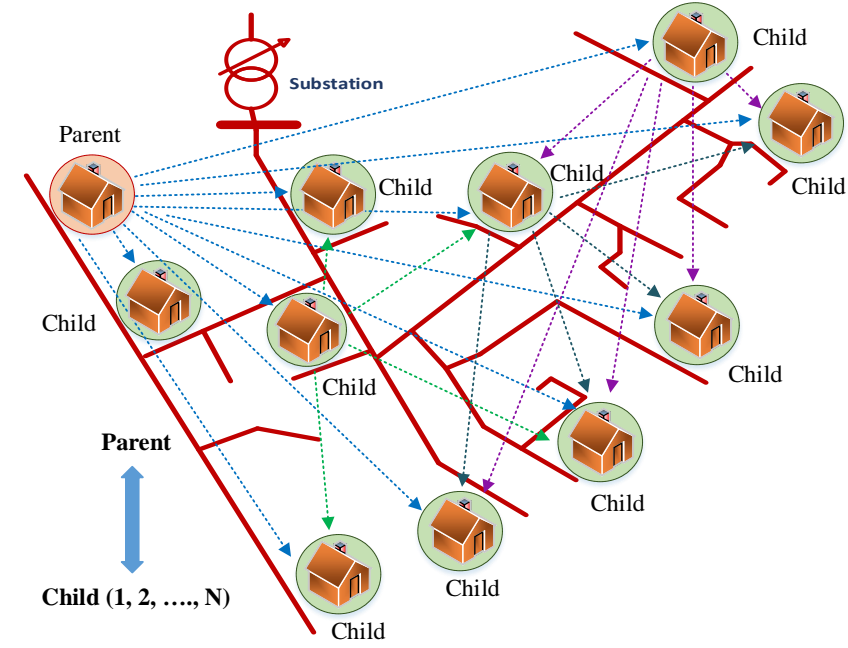

Fig. 3. Potential parent-child searching process.

\section{MANAGEMENT AlgORITHM}

The architecture of the energy transactions between parent and child is shown in Figure 4. The energy resources of the parent are assumed as roof-top PV, battery storage and EV. The child is assumed to have limited energy resources such as roof-top PVs only or may entirely depend on the grid. In the case of the parent, the domestic appliances and EV are connected to a common AC bus. The EV has a V2G-capable charger that enables bidirectional energy transactions. The battery storage and roof-top PV is connected to an intermediate DC bus through a bidirectional DC-DC and a unidirectional DC-DC converter, respectively. The intermediate $\mathrm{DC}$ bus is again connected to the main $\mathrm{AC}$ bus through a bidirectional DC-AC/AC-DC converter. A supervisory controller reads the battery state-of-charge (SOC), load status (peak or off-peak), EV availability and their battery SOC, and PV power generation. Based on these parameters, the controller manages the charging and discharging of the battery storage and EV. On the other hand, if the Child has any roof-top PV, it is connected to the Child's main AC bus through a unidirectional DC-AC converter. The PV power generation (if available) and power demand of the Child are forecasted using the autoregressive moving average (ARMA) and artificial neural networks (ANN) methods. The reason for using two different methods is to investigate their forecasting performance while predicting the consumers' power demand.

The primary objective of the proposed system is to minimize the peak power demand of both electricity sellers (parents) and electricity buyers (children) using P-P energy transactions. In this peak power demand management process, it is required to minimize the distance and demand-generation gap between parent and child. The demand-generation gap is the difference between demand requested by the children and the availability of energy from a parent. The optimization is carried out to minimize this demand-generation gap and distances. After optimization, once the optimal parent-child pair is found, the controller in the parent (energy seller) calculates the available power to sell, and at the same time it forecasts the load demand of the paired child. Based on this load forecast, the parent's controller decides the required power of its paired child to shave the peak, and the power is shared with the child based on parents' selling capability.

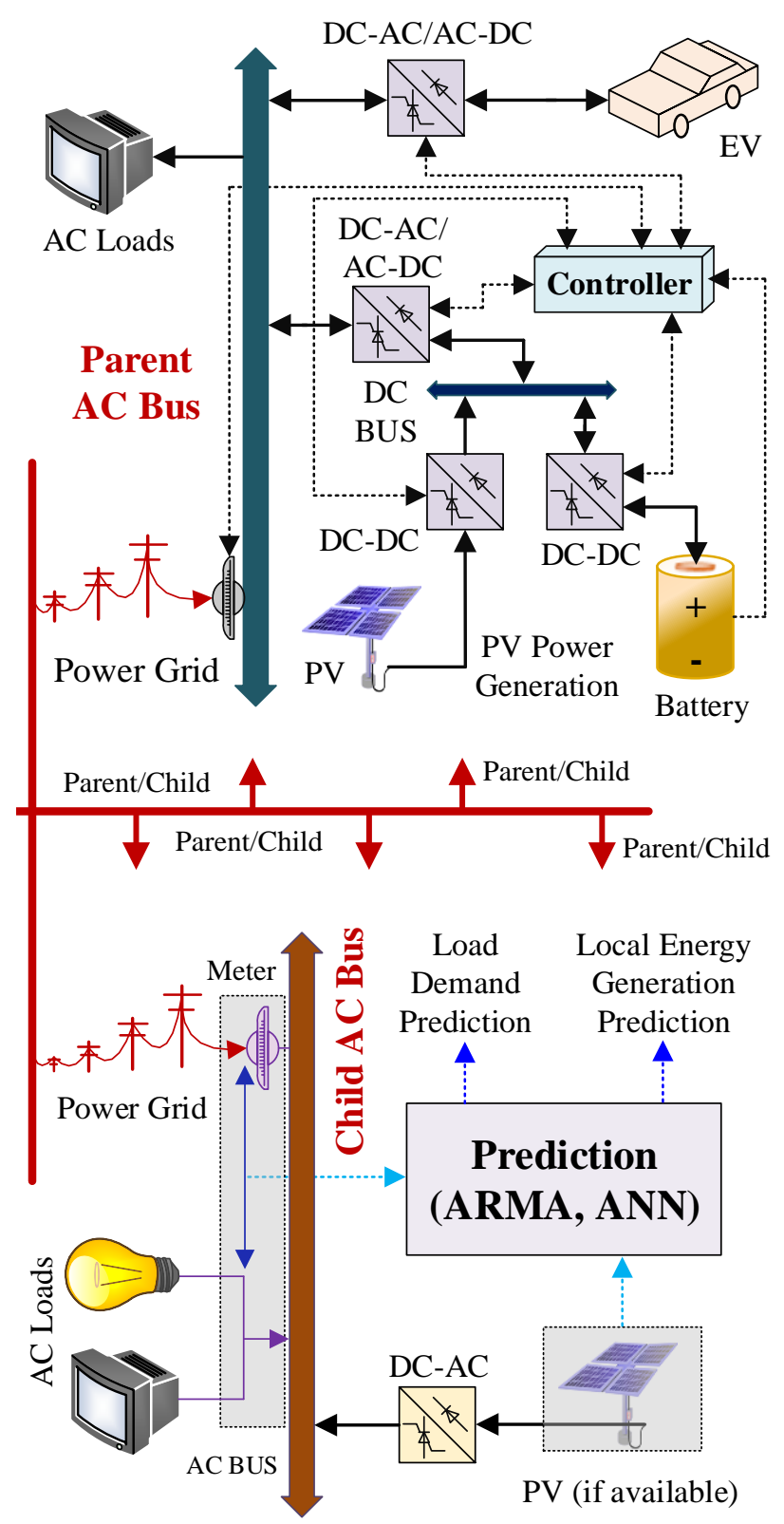

Fig.4. The architecture of the peer-to-peer energy transactions between a parent and a child.

The proposed system can be implemented by any mobile application regulated by the utilities. All the potential and interested consumers and prosumers, i.e. the parents and children need to subscribe the application. Any regulatory body (i.e. utilities, or other govt. agencies) needs to regulate the application to maintain its authenticity and facilitate its compatibility to local standards.

The objective function can be written as:

$$
\min \sum_{p} \sum_{c} x_{p, c} F_{p, c}^{1} F_{p, c}^{2}
$$


Subject to:

energy generation limit of a parent $p$ :

$$
\sum_{p} F_{p, c}^{2}, \chi_{p=1,2, \ldots, m}^{a v} \leq \chi_{p=1,2, \ldots, m}^{\text {capacity }}
$$

Where,

$$
\begin{gathered}
F_{p, c}^{1}=\sum_{p, c=1}^{m}\left(D_{p, c}^{m} \cdot R_{p, c}^{m}\right) \forall p, c \in M \\
F_{p, c}^{2}=\sum_{p, c=1}^{m}\left(\chi_{p=1,2, \ldots, m}^{a v}-\chi_{c=1,2, \ldots, m}^{r e q}\right) \forall p, c \in M
\end{gathered}
$$

The objective of (1-3) is to select an optimal parent-child combination by minimizing power transfer loss and parentchild generation-demand differences. Here, the indices $p$ and $c$ are denoted for parents and children respectively, $\chi_{p=1,2, \ldots, m}^{\text {capacity }}$ is the total capacity of available energy resources (e.g. PV, $\mathrm{EV}$, battery storages), $F_{p, c}^{1}$ is the energy transfer losses from parents to children. The binary variables, $x_{p, c}$ determines the optimal parent-child combination for minimum power transfer loss during the p-p energy trading. $D_{p, c}^{m}$ is the distance between a parent and child in $\mathrm{km}, m$ is the total number of consumers (potential parents and children) in a specified area, $R_{p, c}^{m}$ is the line resistance in per $\mathrm{km}, F_{p, c}^{2}$ is the differences between a parent's energy generation capability and the demand of a child. $\chi_{p=1,2, \ldots, m}^{a v}$ is the available power from the parents, $\chi_{c=1,2, \ldots, m}^{r e q}$ is requested power from the children and $\chi_{p=1,2, \ldots, m}^{a v}>\chi_{c=1,2, \ldots, m}^{r e q}$.

To calculate the available power by a parent and the requested power by a child, it is essential to identify their load demand. Let us assume that the power demand $\mathcal{L}_{p}^{t}$ of a parent is a function of its active power consumptions over a certain period and expressed as [32]:

$$
\mathcal{L}_{p}^{t}=f\left(\mathcal{L}_{p}^{i, j}, t\right)
$$

Where $\mathcal{L}_{p}^{i, j}$ is the active power demand at $i^{\text {th }}$ time for $j^{\text {th }}$ parent, and $t$ is the operational period. The customer defined setpoint $\hbar_{p}^{t}$ defines the peak and off-peak load periods, which also controls the modes of the power from sources and from/to the main grid. The setpoint can be set above the capacity of local renewable energy generators (i.e. PVs). The peak load mode starts when $\mathcal{L}_{p}^{t}>\hbar_{p}^{t}$ and off-peak load mode starts when $\mathcal{L}_{p}^{t}<\hbar_{p}^{t}$. Let us assume that the parent has battery storage, electric vehicle and roof-top PV having the capacity of $\Gamma_{p, b}^{c}, \Gamma_{p, e v}^{c}$ and $\wp_{p v, p}^{t}$ respectively. During $\mathcal{L}_{p}^{t}<\hbar_{p}^{t}$, the battery storages and EV of the parent are charged using the available power $\aleph_{p}^{a v}=\left\{\hbar_{p}^{t}-\left(\mathcal{L}_{p}^{t}+\wp_{p v, p}^{t}\right)\right\}$, and the charging power is expressed as

$$
\aleph_{p}^{a v} \rightarrow\left\{\Gamma_{p, b}^{c}\left(\frac{1}{e^{-\alpha_{p, b}^{i, i \epsilon t}}}\right)\right\}+\left\{\Gamma_{p, e v}^{c}\left(\frac{1}{e^{-\alpha_{p, e v}^{i, i \epsilon t}}}\right)\right\}
$$

Where $\alpha_{p, b}^{i}$ and $\alpha_{p, e v}^{i}$ are the current state-of-charge (SOC) condition of battery storage and electric vehicles (ranging from 0 to 1), respectively. The term $\left\{\Gamma_{p, b}^{c}\left(\frac{1}{e^{-\alpha_{p, b}^{i, i \epsilon t}}}\right)\right\}$ is the charging rate of the battery storage. The maximum amount of power required by the battery storage at a particular time is $\left\{\Gamma_{p, b}^{c}\left(\alpha_{p, b}^{\max }-\alpha_{p, b}^{i}\right)\right\}$, where $\alpha_{p, b}^{\max }$ is the maximum charging limit of the battery storage. Likewise, the term $\left\{\Gamma_{p, e v}^{c}\left(\frac{1}{e^{-\alpha_{p, e v}^{i, \epsilon t}}}\right)\right\}$ is the charging rate of the electric vehicle. The maximum amount of power required by the electric vehicle at a particular time is $\left\{\Gamma_{p, e v}^{c}\left(\alpha_{p, e v}^{\max }-\alpha_{p, e v}^{i}\right)\right\}$, where $\alpha_{p, e v}^{\max }$ is the maximum charging limit of the parent's EV.

When the load condition of the parent is $\mathcal{L}_{p}^{t}>\hbar_{p}^{t}$, the EV (if available) and battery storage need to provide load-support to the parent. The required load support of the parent is expressed as

$$
\aleph_{p}^{r e q}=\left\{\mathcal{L}_{p}^{t}-\hbar_{p}^{t}-\wp_{p v, p}^{t}\right\}
$$

However, the maximum amount of power that the battery storage and EV can provide is equal to $\left\{\Gamma_{p, b}^{c}\left(\alpha_{p, b}^{i}-\alpha_{p, b}^{\min }\right)\right\}$ and $\left\{\Gamma_{p, e v}^{c}\left(\alpha_{p, e v}^{i}-\alpha_{p, e v}^{\min }\right)\right\}$, respectively. Here, $\alpha_{p, b}^{\min }$ and $\alpha_{p, e v}^{\min }$ are the lower discharging boundary of the battery and EV, respectively. The battery and EV discharging rate to provide the load-support for $\aleph_{p}^{r e q}$ is

$$
\aleph_{p}^{r e q} \rightarrow \underbrace{\left\{\Gamma_{p, b}^{c}\left(1-e^{-\alpha_{p, b}^{i, i \in t}}\right)\right\}}_{\text {battery storage }}+\underbrace{\left\{\Gamma_{p, e v}^{c}\left(1-e^{-\alpha_{p, e v}^{i, i \in t}}\right)\right\}}_{E V}
$$

$$
\begin{gathered}
\text { for } \alpha_{p, b}^{\min }<\alpha_{p, b}^{i, i \in t}<\alpha_{p, b}^{\max }, \alpha_{p, e v}^{\min }<\alpha_{p, e v}^{i, i \in t}<\alpha_{p, e v}^{\max } \text { and } 0 \\
\leq \alpha_{p, e v}^{i, i \in t}, \alpha_{p, b}^{i, i \in t} \leq 1
\end{gathered}
$$

The battery storage and electric vehicles charge and discharge considering the load conditions, i.e. peak and off-peak load conditions. So, battery storage and EV act as a load and source 
depending on their mode of operation. At $i^{\text {th }}$ time for $\mathcal{L}_{p}^{t}<$ $\hbar_{p}^{t}$, the number of loads connected to the AC bus of the parent is

$$
\underbrace{\left\{\Gamma_{p, b}^{c}\left(\frac{1}{e^{-\alpha_{p, b}^{i, i \in t}}}\right)\right\}}_{\text {battery charging }}, \underbrace{\left\{\Gamma_{p, e v}^{c}\left(\frac{1}{e^{-\alpha_{p, e v}^{i, i \in t}}}\right)\right\}}_{\text {EV charging }}, \underbrace{\mathcal{L}_{p}^{t}}_{\text {load demand }}
$$

At $i^{\text {th }}$ time for $\mathcal{L}_{p}^{t}>\hbar_{p}^{t}$, the battery storage and $\mathrm{EV}$ (if available) will function in discharging mode. So, the number of sources connected to the AC bus of the parent is

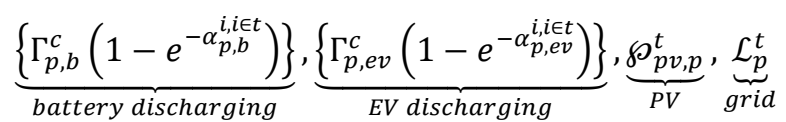

During $\mathcal{L}_{p}^{t}>\hbar_{p}^{t}$, the required grid support $\aleph_{p}^{r e q}$ is provided by the battery storage, EV and PV. If the available energy from the resources is higher than the $\aleph_{p}^{r e q}$, then extra energy is supplied to a child. In order to have a parent to child energy transactions, the following relation should be valid

$\aleph_{p}^{r e q}<\left[\left\{\Gamma_{p, b}^{c}\left(\alpha_{p, b}^{\max }-\alpha_{p, b}^{i}\right)\right\}+\left\{\Gamma_{p, e v}^{c}\left(\alpha_{p, e v}^{\max }-\alpha_{p, e v}^{i}\right)\right\}\right]$

Therefore, the maximum amount of power a parent can share with its child is:

$$
\mathcal{E}_{p-c}^{p}=\left[\left\{\Gamma_{p, b}^{c}\left(\alpha_{p, b}^{\max }-\alpha_{p, b}^{i}\right)\right\}+\left\{\Gamma_{p, e v}^{c}\left(\alpha_{p, e v}^{\max }-\alpha_{p, e v}^{i}\right)\right\}\right]
$$

In this system, a parent's peak power demand management is performed in real-time, where the child's demand management is conducted using day-ahead operation. The child's power demand and renewable energy generation are forecasted using an autoregressive moving average (ARMA) and artificial neural networks (ANN). Once the child's demand is predicted in a day-ahead of the operation, the parent can easily calculate the child's need, and transfer the same amount to the child during real-time operation. This day-ahead operation may help to settle down the energy prices well before the actual operation.

\section{Forecasting using Autoregressive Moving Average}

The autoregressive moving average is a combination of the autoregressive and the moving average, which forecasts using a relationship between its past observation and future values, considering random errors. Let us assume that the child's power demand at $i^{t h}$ time is $\mathcal{L}_{c}^{t}$, and the PV power generation is $\wp_{p v, c}^{t}$. The output $\left(\mathbb{Z}_{t} \in \mathcal{L}_{c}^{t}, \wp_{p v, c}^{t}\right)$ from an AR model is expressed as [33], [34], [35]

$$
\mathbb{Z}_{t}=\sum_{i=1}^{u} \beth_{i} \mathbb{Z}_{t-i}+\beta_{t}+\emptyset
$$

Here, $\beth_{i}$ is the AR model parameter, $u$ is the order, $\emptyset$ is a constant, $\beta_{t}$ is a random error. The random error is a white noise having a constant variance with normal distribution and zero mean. The output from an MA model can be expressed as

$$
\mathbb{Z}_{t}=\partial+\beta_{t}+\sum_{j=1}^{v} \tau_{j} \beta_{t-j}
$$

The mean of the time series is denoted with $\partial$, where $v$ is the MA order, and $\tau_{j}$ is the model parameter. The combination of $\mathrm{AR}$ and MA model, i.e. the output of the ARMA $(u, v)$ model is expressed as [33], [34]

$$
\mathbb{Z}_{t}=\sum_{i=1}^{u} \beth_{i} \mathbb{Z}_{t-i}+\sum_{j=1}^{v} \tau_{j} \beta_{t-j}+\beta_{t}+\emptyset
$$

\section{Forecasting using Artificial Neural Networks}

Artificial neural networks (ANN) performs better to forecast the nonlinear and complex data behavior. The ANN used in this forecasting process has several hidden layers in between the inputs and outputs. The forecasting output $\left(\mathbb{Z}_{t}, \mathbb{Z}_{t} \in \mathcal{L}_{c}^{t}, \wp_{p v, c}^{t}\right)$ from an ANN is expressed as [33], [34], [35]:

$$
\mathbb{Z}_{t}=\sum_{j=1}^{n} \delta_{j} f\left(\theta_{0 j}+\sum_{i=1}^{\varkappa} \theta_{i j} \mathbb{Z}_{t-i}\right)+\varrho_{t}+\delta_{0}, \forall t
$$

It is considered that the ANN model has $n$ number of hidden layers, where weights from the layers are $\theta_{i j}(i=$ $0,1,2, \ldots ., x ; j=0,1,2, \ldots \ldots, n) \quad$ and $\quad \delta_{j}(j=$ $0,1,2, \ldots \ldots, n)$. The $\varrho_{t}$ is a random shock, and $\psi_{0 j}$ and $\delta_{0}$ are the bias term of the ANN.

Let us assume that the set point of a child to identify their power purchase requirement automatically is $\left(\hbar_{c}^{t}\right)$. So, the amount of power a child is willing to purchase is calculated as

$$
\mathcal{E}_{c-p}^{c}=\mathcal{L}_{c}^{t}-\hbar_{c}^{t}
$$

The requested amount of power purchased by a child is $\mathcal{E}_{c-p}^{c}$, where the maximum capacity of power a parent can sell is $\varepsilon_{p-c}^{p}$. While searching a parent-child match, the difference between power selling capability of parent and the power buying request by a child, i.e. $\left(\varepsilon_{p-c}^{p}-\varepsilon_{c-p}^{c}\right)$ is kept at its minimum. 


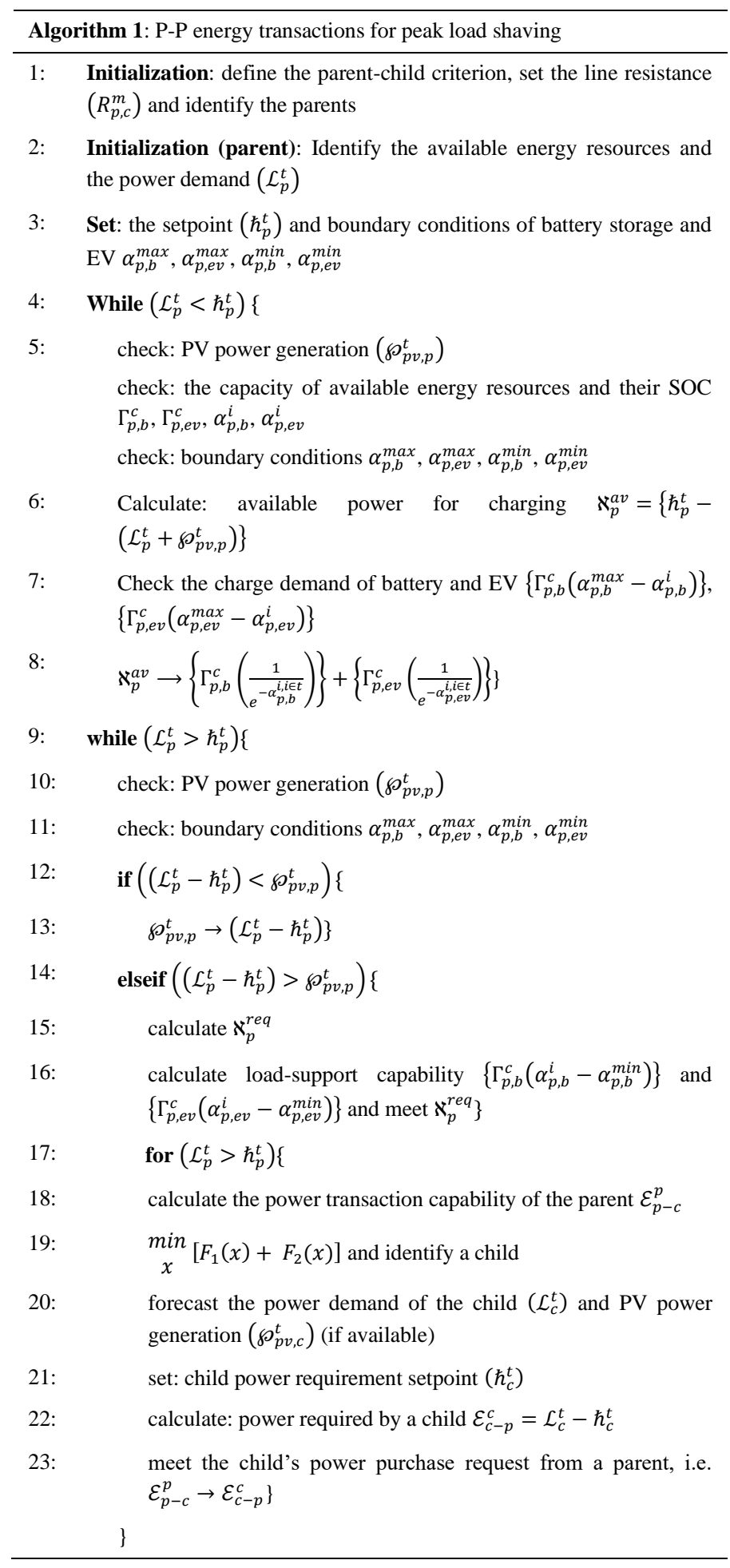

The algorithm for power demand and PV power generation forecasting of a child using ARMA and ANN is shown in algorithm 2 and 3 , respectively.

Algorithm 2: Power demand and PV power generation forecasting of a child using ARMA

1: Initialization: set the power demand and PV power generation parameter of a child $\mathcal{L}_{c}^{t}, \mathcal{L}_{c}^{t-1}, \mathbb{Z}_{t-1}, \mathbb{Z}_{t}, \wp_{p v, c}^{t-1}, \wp_{p v, c}^{t}$ where $\left(\wp_{p v, c}^{t}, \wp_{p v, c}^{t}, \mathcal{L}_{c}^{t-1}, \mathcal{L}_{c}^{t}\right) \in\left(\mathbb{Z}_{t-1}, \mathbb{Z}_{t}\right)$

2: $\quad$ Set: the model $\operatorname{ARMA}(u, v)$ model order $u$ and $v$
3: set the $\mathcal{L}_{c}^{t-1}$ and $\wp_{p v, c}^{t-1}$ to forecast $\mathcal{L}_{c}^{t}$ and $\wp_{p v, c}^{t-1}$, where $\left(\wp_{p v, c}^{t}, \wp_{p v, c}^{t}, \mathcal{L}_{c}^{t-1}, \mathcal{L}_{c}^{t}\right) \in\left(\mathbb{Z}_{t-1}, \mathbb{Z}_{t}\right)$

4: $\quad$ tune $u$ and $v$ to adjust the performance of $\wp_{p v, c}^{t}$ and $\mathcal{L}_{c}^{t}$

Algorithm 3: Power demand and PV power generation forecasting of a child using ANN

Initialization: set the power demand and $\mathrm{PV}$ power generation parameter of a child, and input output of the model $\mathcal{L}_{c}^{t}, \mathcal{L}_{c}^{t-1}, \mathbb{Z}_{t-1}$, $\mathbb{Z}_{t}, \wp_{p v, c}^{t-1}, \wp_{p v, c}^{t}$ where $\left(\wp_{p v, c}^{t}, \wp_{p v, c}^{t}, \mathcal{L}_{c}^{t-1}, \mathcal{L}_{c}^{t}\right) \in\left(\mathbb{Z}_{t-1}, \mathbb{Z}_{t}\right)$

set the processing algorithm to Bayesian Regularization.

set the hidden layer number $n$

train the neural networks for child's power demand using $\mathcal{L}_{c}^{t-1}$, where $\left(\mathcal{L}_{c}^{t-1}\right) \in\left(\mathbb{Z}_{t-1}, \mathbb{Z}_{t}\right)$

train the neural networks for child's PV power generation capacity using $\wp_{p v, c}^{t-1}$, where $\left(\wp_{p v, c}^{t-1}\right) \in\left(\mathbb{Z}_{t-1}, \mathbb{Z}_{t}\right)$

Forecast the $\wp_{p v, c}^{t}$ and $\mathcal{L}_{c}^{t}$

A brief overview of the algorithm 1 is further described using a flowchart in Figure 5.

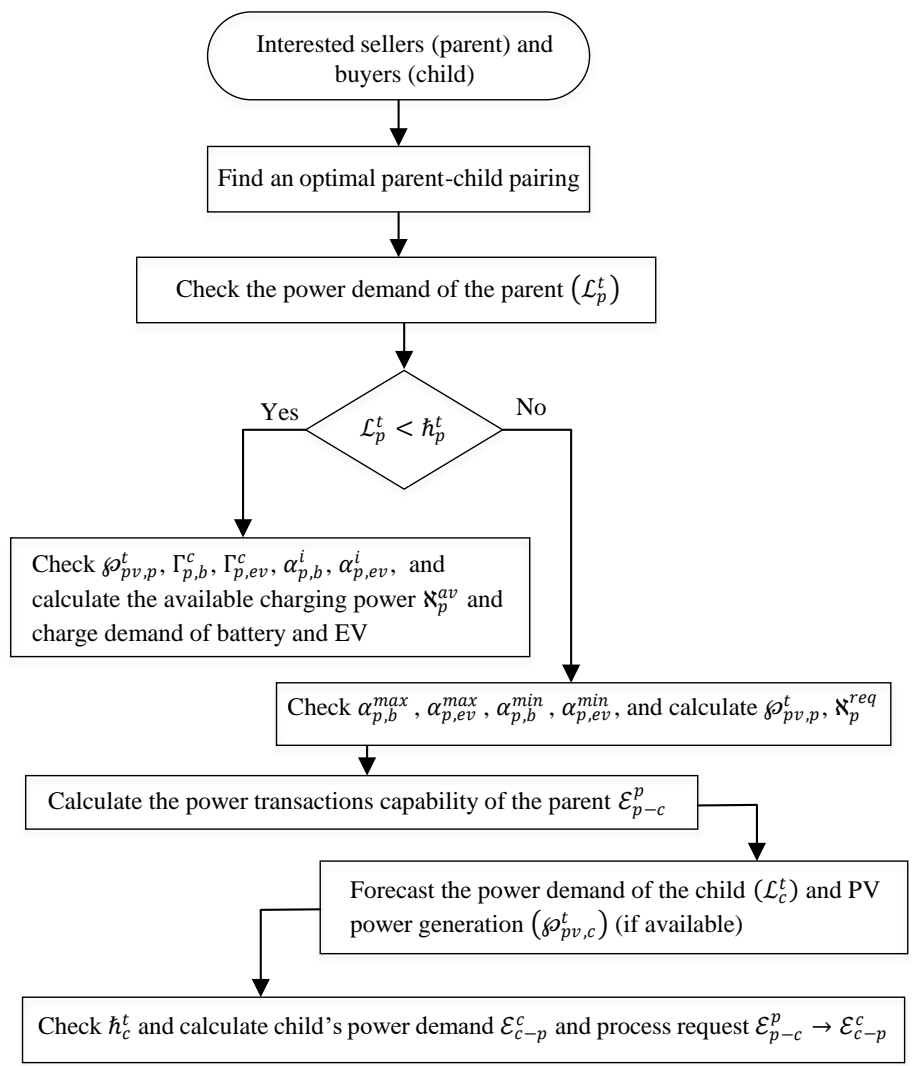

Fig. 5. Flowchart of the P-P energy transactions for peak load shaving.

\section{CASE Studies}

For the case studies, a mixed integer linear programming (MILP) is used to minimize the distances and demandgeneration differences between parent and child. In this case, two potential parent and four potential children were considered. The priority of choosing a particular child by a parent follows an inverse relationship with the distances between them, as shown in Figure 6. 


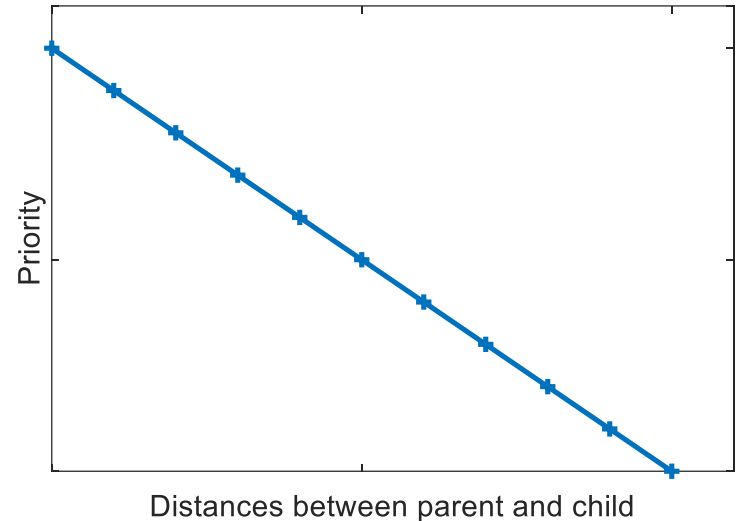

Fig. 6. Distances between parent and child and their matching priority.

The parent and child may have a different power selling capability and different power demand requirements. They will get the maximum preference likelihood and highest parent-child matching priority when the parent's power-selling capability matches with the child's demand, as shown in Figure 7.

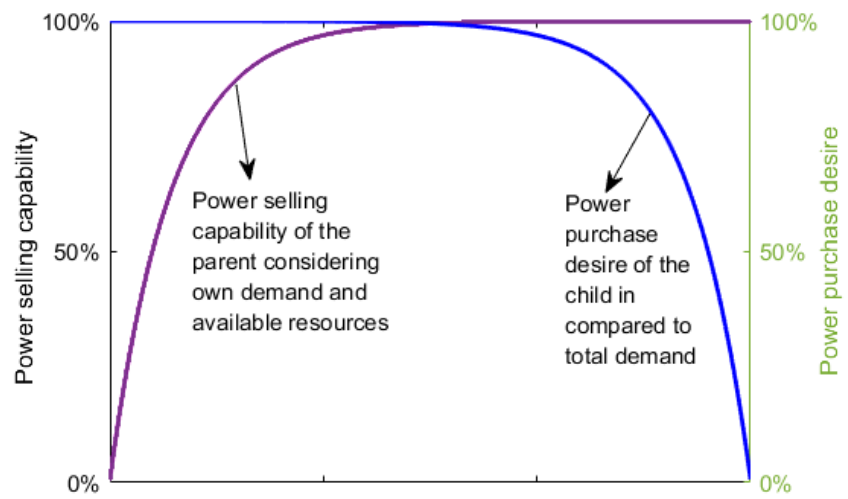

Fig. 7. Parent-child matching priority based on the parent's power-selling capability and child's need.

The MILP problem of (1) is formulated in General Algebraic Modeling System (GAMS) language and solved using CPLEX optimization solver, which uses presolve and branch-and-cut algorithms to reduce the computation time of mixed-integer problems. On a computer with dual-core $2.30 \mathrm{GHz} \mathrm{CPU}$ and $8.00 \mathrm{~GB}$ of RAM, the computation time is lower than 1 second. The optimality gap (both absolute and relative) is 0 since this was explicitly specified in the GAMS model. Once a parent-child association is selected, the system will forecast the power demand of the child and the roof-top PV of the child if available. The ARMA and ANN techniques are used for the forecasting. In this case study, the power demands of two different children having different energy consumption behavior are selected to investigate the performance of the forecasting techniques, ARMA and ANN, as shown in Figure 8 and 9. Figure 8 shows that the ARMA-based forecasting techniques track the nonlinear lines closely, whereas the ANN-based forecasting technique better follows the overall load profile pattern. The performance of the ARMA based forecasting technique is highly dependent on the model order, as shown in (12-14). So, a proper tuning is required to get the optimal performance of the forecasting. The ARMA model order is set to 56 , i.e. $u=56, v=56$, for the forecasting conducted in Figure 8 [35].

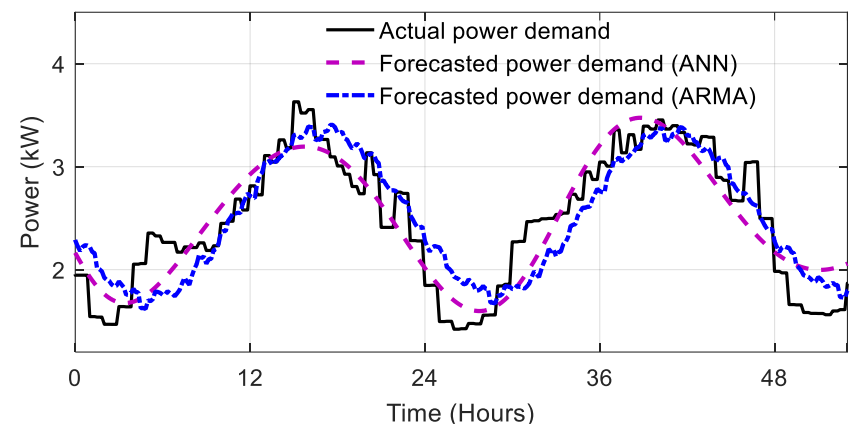

Fig. 8. Power demand forecast of child 1.

Another child having a different load pattern with a higher level of demand fluctuation is chosen to check the performance of the ARMA and ANN-based forecasting, as shown in Figure 9 [35]. The figure shows that the ANN-based technique tracks the power demand profile effectively, while the ARMA-based technique provides a higher rate of error.

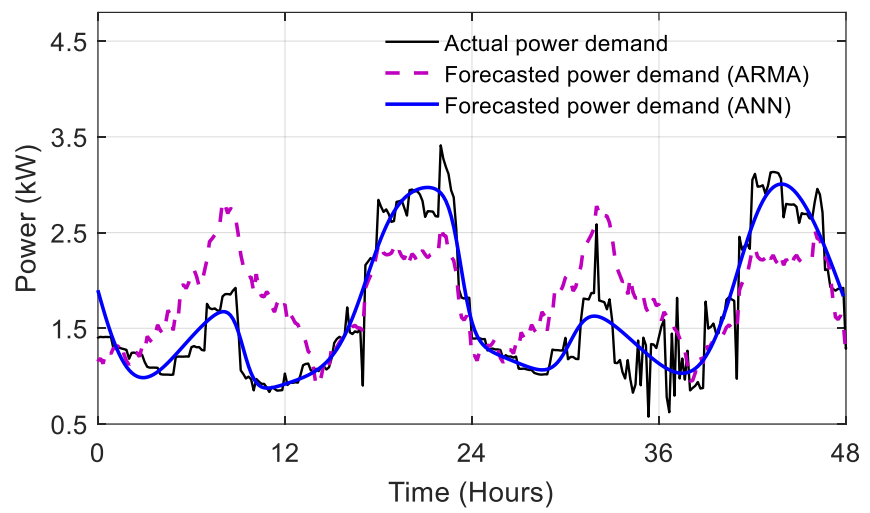

Fig. 9. Power demand forecast of child 2.

The performance and the power sharing quantity is dependent on the load demand forecast. The performance of the power demand forecasting for child 2 during high load fluctuating condition is shown in Figure 10 [35]. It shows the forecasting robustness during load demand uncertainty.

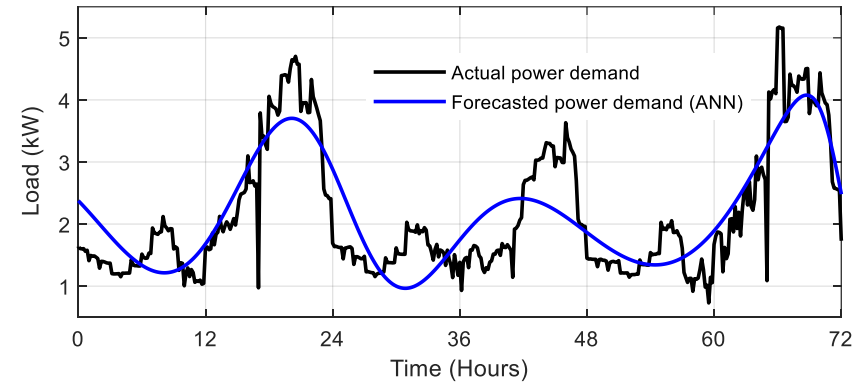

Fig. 10. Power demand forecast of child 2 during high load fluctuation conditions.

When the power demand forecasting of the children is conducted, their individual renewable energy (PV power) generation capability is also considered. The performance of the PV power generation forecast using ANN and ARMA is shown in Figure 11 [35]. 


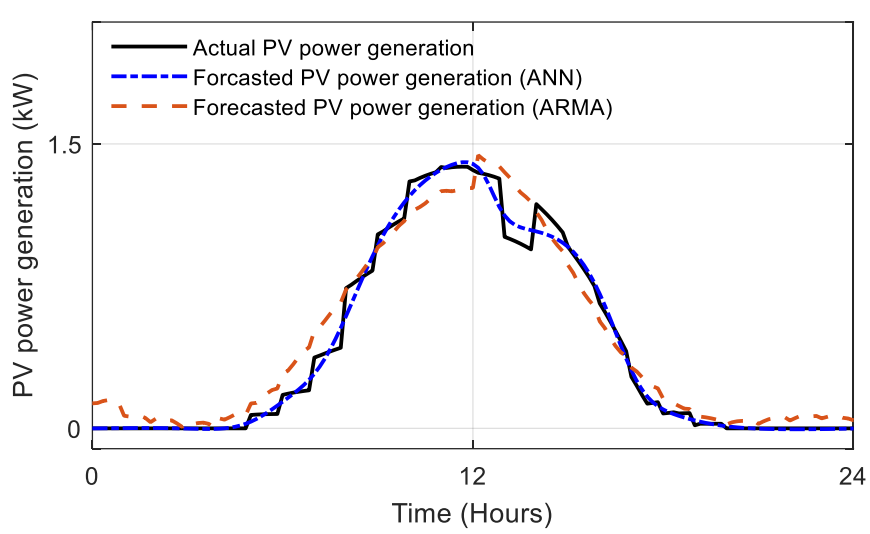

Fig. 11. PV power generation forecasting.

TABLE I

PARAMETER USED DURING THE CASE STUDIES.

\begin{tabular}{|l|l|}
\hline \multicolumn{1}{|c|}{ Parameter } & \multicolumn{1}{c|}{ Values } \\
\hline Energy resources of the parent 1 & $\begin{array}{l}\Gamma_{p, b}^{c}=5 \mathrm{kWh}, \Gamma_{p, e v}^{c}=24 \mathrm{kWh}, \\
\wp_{p v, p}^{t}=1.5 \mathrm{~kW}\end{array}$ \\
\hline Energy resources of the parent 2 & $\Gamma_{p, b}^{c}=8 \mathrm{kWh}, \wp_{p v, p}^{t}=1.5 \mathrm{~kW}$ \\
\hline $\begin{array}{l}\text { Boundary conditions of battery } \\
\text { storage }\end{array}$ & $\alpha_{p, b}^{\min }=30 \%, \alpha_{p, b}^{\max }=95 \%$ \\
\hline Boundary conditions of EV & $\alpha_{p, e v}^{\min }=85 \%, \alpha_{p, e v}^{\max }=95 \%$ \\
\hline
\end{tabular}

The proposed energy management algorithm is used to manage the power demand of the parent. After managing the demand of a parent, extra energy is transferred to a child. Two different parents having different energy resources capability and power demands are chosen in order to investigate the performance of demand management. Figure 12 shows the grid power demand conditions before and after the load management of parent 1 . The figure shows that the grid load demand reduces after using energy management.

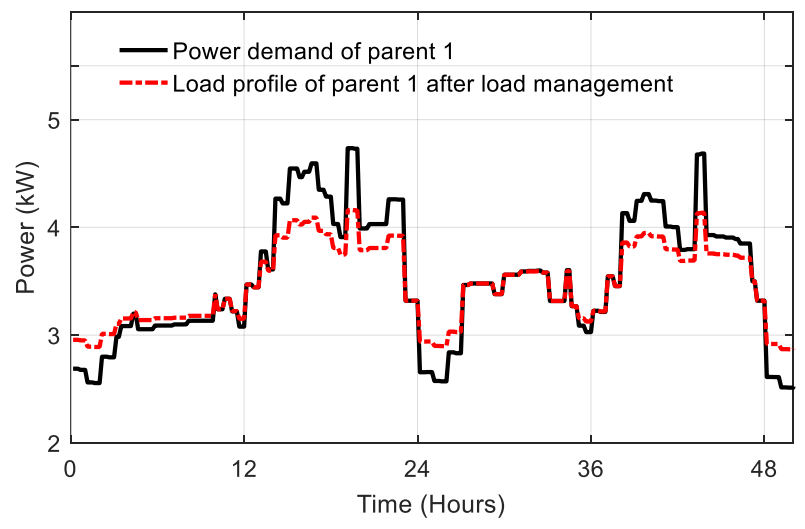

Fig. 12. Demand management of parent 1.

Likewise, the use of demand management for parent 2 reduces the grid load demand significantly, as shown in Figure 13. During the simulation, the power demands of consumers were read from the main meter, as shown in the black lines in Figure 12 and 13. After demand management, the peak load demand is met using the local sources (PV, battery storages and/or EV), which reduced the power drawn from the grid, as shown by the red dotted line in Figure 12 and 13.

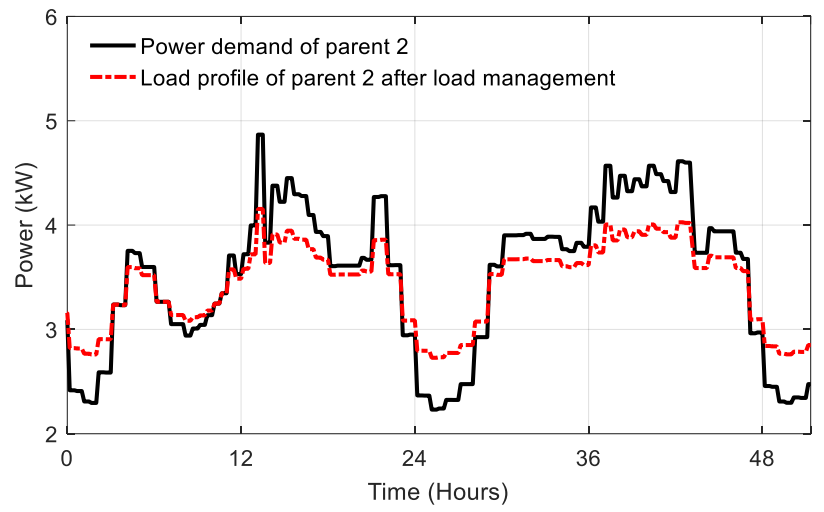

Fig. 13. Demand management of parent 2.

After the demand management of the parent, the available power is calculated considering the available resources and their boundary conditions. The available power after the demand management from parent 1 is transferred to the child 1. In this case, the forecasted load demand instead of the real load demand of child 1 is taken into consideration. The forecasting process minimizes the use of real-time communication hassle between parent and child. Based on the forecasted power demand, the parent gets the idea about the requirement of the child. As the parent already calculated its available power after meeting its demand, the information about the required power of the child helps the parent to calculate the amount of power to be transferred to a child in a day-ahead of the actual operation. This day-ahead operation may help to settle down the energy prices well before the actual operation. Figure 14 and 15 shows the amount of power transferred to the child 1 and 2 from parent 1 and 2 , respectively.

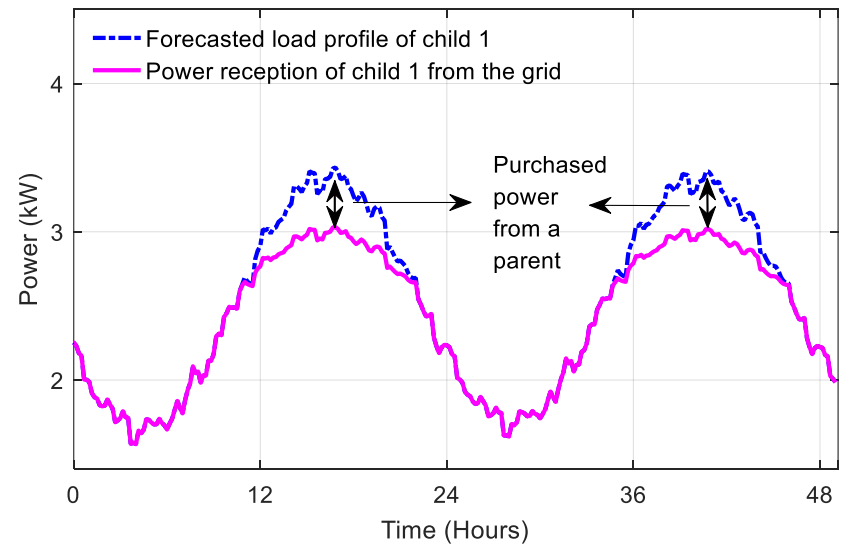

Fig. 14. Power purchase of child 1 and grid load demand conditions.

It is apparent from the figures that the purchasing power from the parent reduces the peak power demand of the child. So, it is expected that the electricity costs of the child will reduce significantly if the time-of-use (ToU) or other similar types of tariff systems are used. Moreover, during the 
infrastructure development and system design phases, this short-term peak demand leads to the use of overcapacity of devices, such as distribution transformer, control and protection systems. Additionally, the peak demand relatively in the evening (having less PV power generation) drives the utilities to provide power from the expensive sources than the base-load generators. The peak load demand could also risk the oversaturation of distribution transformer. Therefore, it is expected that the proposed peak demand management will help consumers to reduce their electricity costs, and the utilities to maintain reliable operation of their system.

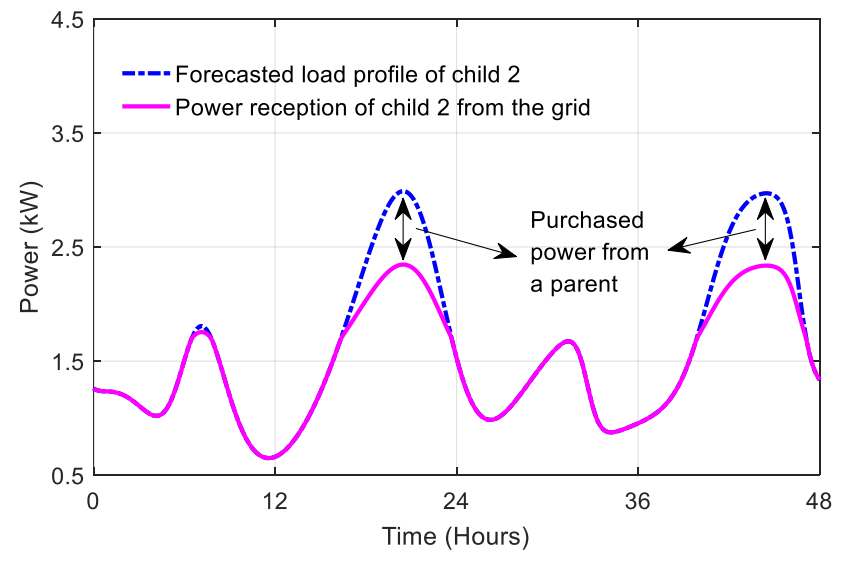

Fig. 15. Power purchase of child 2 and its grid load demand conditions.

The proposed method is compared with the existing literature [27], [13] and [28]. Authors in [27] proposed a multi-agent based system that prevent the rebound peaks. It involves both P-P trading among peers and transactive trading between prosumers and grid operator to prevent transformer overloading. Key findings of the paper are listed in Table II.

TABLE II

FINDINGS IN THE STUDY IN [27].

\begin{tabular}{|c|c|c|c|c|c|c|c|c|c|c|c|}
\hline \multicolumn{6}{|c|}{ Aggregated } & \multicolumn{6}{|c|}{ Single consumer } \\
\hline \multicolumn{2}{|c|}{$\begin{array}{l}\text { Peak } \\
\text { demand }\end{array}$} & \multicolumn{2}{|c|}{$\begin{array}{l}\text { Avg. } \\
\text { demand }\end{array}$} & \multicolumn{2}{|l|}{ PAR } & \multicolumn{2}{|c|}{$\begin{array}{l}\text { Peak } \\
\text { demand }\end{array}$} & \multicolumn{2}{|c|}{$\begin{array}{l}\text { Avg. } \\
\text { demand }\end{array}$} & \multicolumn{2}{|c|}{ PAR } \\
\hline 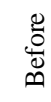 & 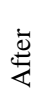 & $\begin{array}{l}0 \\
\stackrel{0}{0} \\
\infty\end{array}$ & 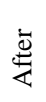 & $\begin{array}{l}0 \\
\stackrel{0}{0} \\
\stackrel{0}{0}\end{array}$ & $\frac{\bar{E}}{<}$ & $\begin{array}{l}0 \\
\frac{0}{0} \\
\infty\end{array}$ & $\stackrel{\bar{E}}{\frac{E}{4}}$ & $\begin{array}{l}0 \\
\frac{0}{0} \\
\infty\end{array}$ & $\underbrace{\overline{4}}_{\frac{E}{4}}$ & $\begin{array}{l}0 \\
\frac{0}{0} \\
\infty\end{array}$ & 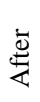 \\
\hline$\stackrel{\Omega}{=}$ & 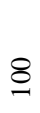 & $\frac{a}{\stackrel{\text { f }}{\text { mे }}}$ & 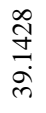 & $\begin{array}{l}\bar{\kappa} \\
\stackrel{i}{i}\end{array}$ & $\begin{array}{l}\text { 苟 } \\
\tilde{n} \\
i\end{array}$ & $\begin{array}{l}\text { त̃ } \\
\text { } \\
+\end{array}$ & $\hat{\widehat{i}}$ & 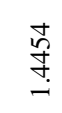 & $\begin{array}{l}\bar{\infty} \\
n \\
n \\
n\end{array}$ & $\begin{array}{l}\overline{\widetilde{a}} \\
\text { ה }\end{array}$ & $\bar{g}$ \\
\hline
\end{tabular}

Note: All values are in $\mathrm{kW}$, peak-to-average ratio (PAR)

Authors in [13] proposed a game-theory based local energy sharing among peers. It minimizes electricity cost, peak demand and peak to average ration (PAR). Key findings (only aggregated results for the neighborhood) of the paper are listed in Table III.

TABLE III

FINDINGS IN THE STUDY IN [13].

\begin{tabular}{|l|l|l|l|}
\hline \multicolumn{4}{|c|}{ Summer Season } \\
\hline Algorithm & Peak value $(\mathrm{kW})$ & Average Value $(\mathrm{kW})$ & PAR \\
\hline Non-cooperative & 36.005 & 18.711 & 1.92 \\
\hline
\end{tabular}

\begin{tabular}{|l|l|l|l|}
\hline scheduling & \multicolumn{1}{|c|}{} & \\
\hline CCA scheduling & 33.914 & 18.127 & 1.87 \\
\hline $\begin{array}{l}\text { Game-theory } \\
\text { approach }\end{array}$ & 32.913 & 18.682 & 1.76 \\
\hline \multicolumn{3}{|c|}{ Winter Season } \\
\hline $\begin{array}{l}\text { Non-cooperative } \\
\text { scheduling }\end{array}$ & 30.7 & 15.69 & 1.95 \\
\hline CCA scheduling & 28.41 & 15.44 & 1.84 \\
\hline $\begin{array}{l}\text { Game-theory } \\
\text { approach }\end{array}$ & 29.17 & 16.04 & 1.81 \\
\hline
\end{tabular}

Authors in [28] proposed an energy sharing system among peers. It uses a multi-agent based coordinated method to reduce peak demand, over-voltage and under-voltage. The key findings (only aggregated results for the LV feeder) of the paper are listed in Table IV.

TABLE IV

FINDINGS IN THE STUDY IN [28]

\begin{tabular}{|l|l|l|}
\hline \multicolumn{3}{|c|}{ Summer } \\
\hline Peak demand & Case 1-peak & Case 2 - peak \\
\hline 103.32 & 93.1 & 92.25 \\
\hline \multicolumn{3}{|c|}{ Winter } \\
\hline Peak demand & Case 1- peak & Case 2 - peak \\
\hline 106.63 & 98.91 & 99.66 \\
\hline
\end{tabular}

The proposed method is compared with the findings in Table II, III and IV, and listed in Table V.

TABLE V

COMPARISON OF THE PROPOSED METHOD WITH THE EXISTING LITERATURE.

\begin{tabular}{|l|l|l|l|l|}
\hline & Ref [27] & Ref [13] & Ref [28] & $\begin{array}{l}\text { Proposed } \\
\text { method }\end{array}$ \\
\hline $\begin{array}{l}\text { Peak demand } \\
\text { reduction }\end{array}$ & $15 \%$ & $8.59 \%$ & $10.71 \%$ & $14.63 \%$ \\
\hline PAR reduction & $6.03 \%$ & $8.33 \%$ & $10.46 \%$ & $12.85 \%$ \\
\hline
\end{tabular}

The peak demand reduction is higher in [27], however, it only reduces peak demand beyond maximum transformer loading. Therefore, it does not reduce demand peaks when aggregated transformer load is below its maximum capacity. As a result, its peak to average ration (PAR) reduction is the lowest. The proposed method performs better in all other aspects.

\section{CONCLUSION}

The main goal of the study was to develop a P-P energy transaction system to minimize the domestic peak load demand. In this process, the prosumers willing to participate in the energy buying and selling process are identified, and their power demand and energy generation capability were calculated. As the power demand profile is an important parameter in the energy transaction process, two different forecasting techniques were used to predict the prosumers power consumption behavior. The proposed method is tested using various investigations based on data of a real Australian power distribution network. The results of these investigations show that the proposed method minimizes the peak load 
demand up to $14.63 \%$ for both energy selling and energy buying customers, which is expected to reduce the electricity costs. Moreover, it also reduces the peak-to-average ratio by $12.85 \%$. The insights gained from this study may be of assistance to the rapidly expanding field of P-P energy transactions, prosumers and the virtual power plant. The research has resulted in several insights, leading to further scope of studies such as the impact of prediction errors to the P-P process, the power flow behavior at the substation point and its implications to the distribution transformer.

\section{REFERENCES}

[1] F. Yang, X. Feng, and Z. Li, "Advanced Microgrid Energy Management System for Future Sustainable and Resilient Power Grid," IEEE Trans. Ind. Appl., p. 1, 2019.

[2] F. Delfino, G. Ferro, M. Robba, and M. Rossi, “An Energy Management Platform for the Optimal Control of Active and Reactive Power in Sustainable Microgrids," IEEE Trans. Ind. Appl., p. 1, 2019.

[3] T. Khalili, A. Jafari, and E. Babaei, "Scheduling and siting of storages considering power peak shaving and loss reduction by exchange market algorithm," in 2017 Smart Grid Conference (SGC), 2017, pp. 1-7.

[4] S. G. Faddel and O. A. Mohammed, "Automated Distributed Electric Vehicle Controller for Residential Demand Side Management," IEEE Trans. Ind. Appl., p. 1, 2018.

[5] T. Khalili, M. T. Hagh, S. G. Zadeh, and S. Maleki, "Optimal reliable and resilient construction of dynamic self-adequate multi-microgrids under large-scale events," IET Renew. Power Gener., 2019.

[6] A. Paudel, K. Chaudhari, C. Long, and H. B. Gooi, "Peer-to-Peer Energy Trading in a Prosumer-Based Community Microgrid: A Game-Theoretic Model," IEEE Trans. Ind. Electron., vol. 66, no. 8, pp. 6087-6097, 2019.

[7] E. Mashhour and S. M. Moghaddas-Tafreshi, "Bidding Strategy of Virtual Power Plant for Participating in Energy and Spinning Reserve Markets-Part I: Problem Formulation,” IEEE Trans. Power Syst., vol. 26, no. 2, pp. 949-956, 2011.

[8] J. Soares, H. Morais, T. Sousa, Z. Vale, and P. Faria, "Day-Ahead Resource Scheduling Including Demand Response for Electric Vehicles," IEEE Trans. Smart Grid, vol. 4, no. 1, pp. 596-605, 2013.

[9] W. Tushar et al., "Energy Storage Sharing in Smart Grid: A Modified Auction-Based Approach," IEEE Trans. Smart Grid, vol. 7, no. 3, pp. 1462-1475, 2016.

[10] M. H. Cintuglu, H. Martin, and O. A. Mohammed, "Real-Time Implementation of Multiagent-Based Game Theory Reverse Auction Model for Microgrid Market Operation," IEEE Trans. Smart Grid, vol. 6, no. 2, pp. 1064-1072, 2015.

[11] S. Cui, Y. Wang, and N. Liu, "Distributed game-based pricing strategy for energy sharing in microgrid with PV prosumers," IET Renew. Power Gener., vol. 12, no. 3, pp. 380-388, 2018.

[12] N. Liu, X. Yu, C. Wang, C. Li, L. Ma, and J. Lei, "Energy-sharing model with price-based demand response for microgrids of peer-to-peer prosumers," IEEE Trans. Power Syst., vol. 32, no. 5, pp. 3569-3583, 2017.

[13] E. Fernandez, M. J. Hossain, and M. S. H. Nizami, "Game-theoretic approach to demand-side energy management for a smart neighbourhood in Sydney incorporating renewable resources," Appl. Energy, vol. 232, pp. 245-257, 2018.

[14] Y. Wang, W. Saad, Z. Han, H. V Poor, and T. Başar, "A GameTheoretic Approach to Energy Trading in the Smart Grid," IEEE Trans. Smart Grid, vol. 5, no. 3, pp. 1439-1450, 2014.

[15] W. Lee, L. Xiang, R. Schober, and V. W. S. Wong, "Direct Electricity Trading in Smart Grid: A Coalitional Game Analysis," IEEE J. Sel. Areas Commun., vol. 32, no. 7, pp. 1398-1411, 2014.

[16] N. Wang, W. Xu, Z. Xu, and W. Shao, "Peer-to-Peer Energy Trading among Microgrids with Multidimensional Willingness," Energies, vol. 11, no. 12, p. 3312, 2018.

[17] C. Long, J. Wu, C. Zhang, L. Thomas, M. Cheng, and N. Jenkins, "Peerto-peer energy trading in a community microgrid," in 2017 IEEE Power \& Energy Society General Meeting, 2017, pp. 1-5.

[18] K. Mahmud, A. K. Sahoo, J. Ravishankar, and Z. Y. Dong, "Coordinated Multilayer Control for Energy Management of Grid-Connected AC Microgrids," IEEE Trans. Ind. Appl., 2019.

[19] K. Mahmud, M. S. H. Nizami, M. J. Hossain, and J. Ravishankar, "A
Home-to-Home Energy Sharing Process for Domestic Peak Load Management," 2018 IEEE Int. Conf. Environ. Electr. Eng. 2018 IEEE Ind. Commer. Power Syst. Eur. (EEEIC / I\&CPS Eur., pp. 1-5, Jun. 2018.

[20] C. Chen, J. Wang, Y. Heo, and S. Kishore, "MPC-based appliance scheduling for residential building energy management controller," IEEE Trans. Smart Grid, vol. 4, no. 3, pp. 1401-1410, 2013.

[21] A. Y. Saber and G. K. Venayagamoorthy, "Resource scheduling under uncertainty in a smart grid with renewables and plug-in vehicles," IEEE Syst. J., vol. 6, no. 1, pp. 103-109, 2012.

[22] T. Khalili, S. Nojavan, and K. Zare, "Optimal performance of microgrid in the presence of demand response exchange: A stochastic multiobjective model," Comput. Electr. Eng., vol. 74, pp. 429-450, 2019.

[23] K. Mahmud, M. J. Hossain, and G. E. Town, "Peak-Load Reduction by Coordinated Response of Photovoltaics, Battery Storage, and Electric Vehicles," IEEE Access, vol. 6, 2018.

[24] M. L. Di Silvestre et al., "Ancillary Services in the Energy Blockchain for Microgrids," IEEE Trans. Ind. Appl., 2019.

[25] T. Morstyn, A. Teytelboym, and M. D. Mcculloch, "Bilateral Contract Networks for Peer-to-Peer Energy Trading," IEEE Trans. Smart Grid, vol. 10, no. 2, pp. 2026-2035, 2019.

[26] E. Sorin, L. Bobo, and P. Pinson, "Consensus-based approach to peer-topeer electricity markets with product differentiation," IEEE Trans. Power Syst., vol. 34, no. 2, pp. 994-1004, 2018.

[27] M. S. H. Nizami, J. Hossain, and E. Fernandez, "Multi-Agent Based Transactive Energy Management Systems for Residential Buildings with Distributed Energy Resources," IEEE Trans. Ind. Informatics, 2019.

[28] M. S. H. Nizami, A. Haque, P. H. Nguyen, and M. J. Hossain, "On the application of Home Energy Management Systems for power grid support," Energy, vol. 188, p. 116104, 2019.

[29] W. Tushar, T. K. Saha, C. Yuen, P. Liddell, R. Bean, and H. V. Poor, "Peer-to-Peer Energy Trading With Sustainable User Participation: A Game Theoretic Approach," IEEE Access, vol. 6, pp. 62932-62943, 2018.

[30] J. Kang, R. Yu, X. Huang, S. Maharjan, Y. Zhang, and E. Hossain, "Enabling Localized Peer-to-Peer Electricity Trading Among Plug-in Hybrid Electric Vehicles Using Consortium Blockchains," IEEE Trans. Ind. Informatics, vol. 13, no. 6, pp. 3154-3164, 2017.

[31] A. J. D. Rathnayaka, V. M. Potdar, T. S. Dillon, O. K. Hussain, and E. Chang, "A methodology to find influential prosumers in prosumer community groups," IEEE Trans. Ind. Informatics, vol. 10, no. 1, pp. 706-713, 2014.

[32] K. Mahmud, M. J. Hossain, and J. Ravishankar, "Peak-Load Management in Commercial Systems With Electric Vehicles," IEEE Syst. J., vol. 13, no. 2, pp. 1872-1882, 2019.

[33] R. Adhikari and R. K. Agrawal, "An introductory study on time series modeling and forecasting," arXiv Prepr. arXiv1302.6613, 2013.

[34] P. Su et al., "Recent Trends in Load Forecasting Technology for the Operation Optimization of Distributed Energy System," Energies, vol. 10, no. 9, p. 1303, 2017.

[35] K. Mahmud, J. Ravishankar, M. J. Hossain, and Z. Y. Dong, "The Impact of Prediction Errors in the Domestic Peak Power Demand Management," IEEE Trans. Ind. Informatics, p. 1, 2019.

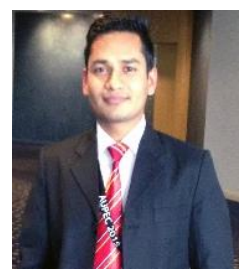

Khizir Mahmud (S'15) received the B.Sc. degree from the Chittagong University of Engineering and Technology, Bangladesh, in 2011, and the M.S. degree from the Northwestern Polytechnical University (NWPU), Xi'an, China, in 2014, and the $\mathrm{PhD}$ degree from the University of New South Wales (UNSW), Sydney, in 2018, all in Electrical Engineering. In 2017, he was a Visiting Researcher at the University of Illinois Urbana-Champaign, USA $\mathrm{He}$ is currently working as a postdoctoral research fellow at the Energy Systems Research Group, School of Electrical Engineering and Telecommunications, UNSW, Sydney, Australia. He is also serving as an editorial board member of the Smart Science Journal, Taylor \& Francis.

Dr. Mahmud received a Chinese Government Scholarship in 2012. He received the WU Yajun Scholarship by NWPU for excellent academic and 
research performance in 2014. He is also the recipient of the Australian Government Research Training Program Scholarship, and the UNSW postdoctoral writing fellowship.

His research interests include smart grid, renewable energy integration to the grid, internet of energy and the virtual power plant.

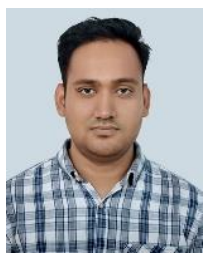

M. S. H. Nizami (S'18) received the B. Sc. degree from Islamic University of Technology, Dhaka, Bangladesh, in 2010 and M.Sc. degree from Eindhoven University of Technology (TU/e), the Netherlands in 2015. He is currently working toward the Ph.D. degree in electrical engineering at Macquarie University, Sydney, NSW, Australia. His Ph.D. research is focused on residential energy management systems for active consumer participation in smart grid services.

His research interests include grid interactive demand response, optimization and energy management systems for active distribution network, electric vehicles, demand side management, and transactive energy management.

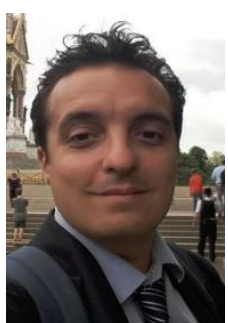

Pierluigi Siano (M'09-SM'14) received the M.Sc. degree in electronic engineering and the Ph.D. degree in information and electrical engineering from the University of Salerno, Salerno, Italy, in 2001 and 2006, respectively. He is a Professor and Scientific Director of the Smart Grids and Smart Cities Laboratory with the Department of Management \& Innovation Systems, University of Salerno.

His research activities are centered on demand response, on the integration of distributed energy resources in smart grids and on planning and management of power systems. He has co-authored more than 450 papers including more than 200 international journal papers that received more than 7600 citations with an $\mathrm{H}$ index equal to 44 . He received the award as 2019 Highly cited Researcher by ISI Web of Science Group. He has been the Chair of the IES TC on Smart Grids. He is Editor for the Power \& Energy Society Section of IEEE Access, IEEE TRANSACTIONS ON INDUSTRIAL INFORMATICS, IEEE TRANSACTIONS ON INDUSTRIAL ELECTRONICS, Open Journal of the IEEE IES and of IET Renewable Power Generation.

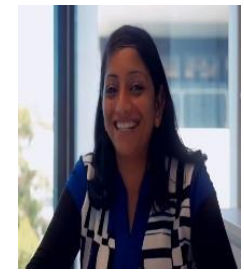

Jayashri Ravishankar (SM'09) received the B.E., M.E., and $\mathrm{Ph} . \mathrm{D}$. degrees in electrical engineering from Anna University, Chennai, India, in 1987, 1992, and 2008, respectively. In 2010, she joined the University of New South Wales (UNSW), Sydney, NSW 2052, Australia, as an Australian Power Institute (API) sponsored academic for promoting power engineering. She was the first CI in API grant for building a microgrid test bench at UNSW. Her research interests include power system modeling, analysis, and control, renewable energy integration, smart grids, and microgrids. She has authored and co-authored more than 80 journal and conference papers in this area. She is a regular reviewer for several IEEE, IET, and other journals and conferences.

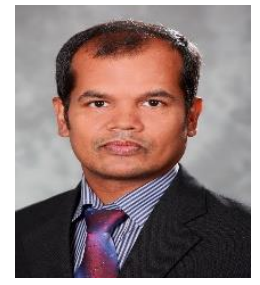

M. J. Hossain (M'10-SM'13) received the B.Sc. and M.Sc. Eng. degrees from Rajshahi University of Engineering and Technology (RUET), Bangladesh, in 2001 and 2005, respectively, and the Ph.D. degree from the University of New South Wales, Australia, all in electrical and electronic engineering. $\mathrm{He}$ is currently an Associate Professor with the Department of Engineering, Macquarie University, Australia. Before joining there, he served as a Senior Lecture and a Lecturer in the Griffith School of Engineering, Griffith University, for five years and as a Research Fellow in the School of Information Technology and Electrical Engineering, University of Queensland, Brisbane, Australia.

His research interests include renewable energy integration and stabilization, voltage stability, micro grids and smart grids, robust control, electric vehicles, flexible ac transmission systems devices, and energy storage systems. 